\title{
MEMORIAL SOBRE A TRAJETÓRIA ESCOLAR BÁSICA DE SHIRLENE DO SOCORRO COELHO SANTOS
}

\author{
Shirlene do Socorro Coelho Santos ${ }^{1}$
}

Resumo: O presente texto trata do memorial sobre a trajetória escolar de Shirlene do Socorro Coelho Santos, ex-integrante do Programa Conexões de Saberes. Tem como objetivo apresentar os passos percorridos desde o início da educação básica até a entrada à UFPA e quais os principais entraves de estudantes das comunidades populares adentrarem o ensino superior público. A memória foi usada como principal referência para construção do material. Em seus resultados, apresenta os esforços individual e coletivo para que de fato a educação seja uma questão de direito e não de privilégio de poucos.

\section{"Vim, esperei, planejei, superei"2}

"Vim, esperei, planejei, superei" é uma frase-lema da carta de Julio César enviada a Cleópatra, por ter lutado e vencido uma guerra muito complicada, fato que o fez mudar o seu lema de: “vim, vi e venci”. Uso o seu lema como resumo deste memorial que será apresentado, pois também vai discorrer sobre uma guerra árdua.

Caros leitores eu chamo este memorial de máquina do tempo, pois neste processo de sujeito histórico, sinto minha vida passar cronologicamente, como em uma série histórica. Como no filme "De volta pra o futuro" no qual Marty McFly (Michael J. Fox) é o típico adolescente norte-americano dos anos de 1980, que é enviado de volta no tempo, para 1955, por uma invenção (o DeLorean) do excêntrico Dr. Brown (Christopher Lloyd). Enquanto estiver no passado, Marty deve tomar cuidado para não interferir em nada, para que o futuro não seja alterado.

Temos muito em comum, assim como ele também sou dos anos de 1980. Não sei, mas fui enviada de volta para esta década, e tenho o desafio de não alterar nada no passado. Mas saibam, não está sendo tão simples

\footnotetext{
1 Especialização em Educação Social para Juventude pela Universidade do Estado do Pará shirleneufpa@ hotmail.com

${ }^{2}$ Ernani Pinheiro Chaves é graduado em Administração pela Universidade Federal do Pará (1978), Mestre em Filosofia pela Pontifícia Universidade Católica de São Paulo (1986) e Doutor em Filosofia pela Universidade de São Paulo (1993). Durante o Doutorado realizou estudos e pesquisas na Faculdade de Teologia (1989-1991) e na Universidade Técnica (1992), ambas em Berlim, Alemanha. Realizou estágio de Pós-Doutorado em 1998, também na Universidade Técnica de Berlim e em 2003 na Bauhaus-Universität, de Weimar, na Alemanha. Atualmente é professor Associado I da Faculdade de Filosofia da Universidade Federal do Pará. Tem experiência na área de Filosofia, com ênfase em Filosofia Alemã, em especial Nietzsche e a Escola de Frankfurt. Além disso, também realiza estudos sobre o pensamento de Michel Foucault e no âmbito da Filosofia da Psicanálise.
}

Revista PET Interdisciplinar e Programa Conexões /UFPA On-line. Ed. Especial - 2017, BELÉM/ PA - ISSN 2447-097X 
Escrever este memorial. Ter que relembrar alguns momentos, que até agora fazia de tudo pra esquecer. Fases onde meus direitos, lema da Revolução Francesa como igualdade e dignidade foram dolorosamente violados. Num primeiro momento recusei a proposta de fazer esse resgate de minha vida, não queria que ninguém soubesse de algumas coisas, ora por vergonha, ora por medo, mas mudei de idéia depois da orientação da professora Maria José Aviz do Rosário, quando nos apresentou seu memorial, passamos a conhecê-la e a pensar que também temos uma chance.

A partir desse momento comecei a ver a produção desse memorial como uma via transformadora de superação, pois sei que não sou nem Cleópatra, nem Marco Antonio, mas me arvoro em dizer: já venci!!!!. Talvez alguém leia e repense a sua vida.

Sou filha de Maria Natividade, não é a santa, mas também é uma mulher admirável que luta até o fim. Não dá para falar de mim sem falar dessa mulher de braço forte e mãos calejadas, talvez eu seja a sua eternidade. Alguém pode dizer: Está aqui a Natividade!. Minha mãe nasceu no Igarapé Castanhal localidade do baixo Acará neste mesmo estado. Começou a trabalhar muito cedo na produção de farinha d'água. Naquele tempo os pais eram muitos rígidos, escolhiam com quem as filhas se casariam, dessa forma achavam que estavam protegendo-as. Com ela foi assim. Com 18 anos foi obrigada a casar com um homem da redondeza (Vitor, meu pai), e logo começou a tormenta. Saibam quando relato isso meus olhos são lavados e meu coração dispara, mas acho que para entender certas coisas isto é preciso...O casamento não deu certo, pois meu pai era alcoólatra. Diante disso ela resolveu fugir, com a ajuda do irmão: o tio Tavinho. Ela se escondeu na mata e quando passou o pau de arara $^{2}$ embarcaram rumo à capital, Belém, em busca de uma vida mais digna. Isso ocorreu ela estava com 2 anos de casada e ainda não tinha engravidado. Quando meu avô soube, a obrigou a voltar com ele.

Meu pai veio para Belém atrás dela, depois de três meses, ela estava grávida de 5 meses, ou seja, ao sair de seu lugar, ou melhor quando veio de lá já estava grávida. Eles ficaram juntos, depois de alguns meses ela deu a luz a uma linda menina negra (eu), em 1984, quando o Brasil passava por uma grande transformação política, mas precisamente a abertura política, a chamada: Diretas Já. Nasci em meio a essa grande transformação nacional, mas paradoxalmente na vida de minha mãe os problemas só começavam. Foi aí que as coisas desandaram. Como acreditar? Ele,meu pai, sendo branco, com uma filha negra, ainda que tivesse casado com uma mulher negra?. Vieram outros filhos os meus cinco irmãos Joelson 
(Preto), Cileia (Leia), Sirley (Cissa) e Carolina (Carol), depois da Carol nasceu o Jailson que morreu com 7 dias de nascido.

Com tantos filhos as coisas pioraram, mais bocas para comer mais preocupações. A cada filho que nascia aumentava o sofrimento, pois tinha que trabalhar mais, isso a fazia pensar que não podia se separar ${ }^{3}$. As brigas entre eles aumentavam a cada dia; minha mãe definhava. Saía as cinco da madrugada para trabalhar na fábrica de castanha-do-pará e chegava às $18 \mathrm{~h}$. Nós, às vezes, nem a víamos, pois quando saía ainda estávamos dormindo, quando chegava já estávamos dormindo. A cada dia a situação de agressões piorava. Quanto chegava quinta-feira já sofríamos, sabíamos que o pai ia beber e quando ele chegasse as agressões continuariam, tanto com nossa mãe quanto com a gente.

Dentro deste processo fomos inseridos na vida escolar. Minha primeira escola foi a "Barracão", era uma escolinha para as crianças da comunidade, chamava-se assim por ser parecida com um galpão, não havia divisão física de salas. Nesta escolinha dei os primeiros passos na vida escolar, depois fui morar com meus avós no interior de Acará - Castanhalzinho município do Pará e lá dei continuidade nos estudos. Estudei até a $4^{\mathrm{a}}$ serie, até que a minha mãe foi me buscar - pensava que o ensino de lá era fraco. Logo voltei à Belém, mas quando chegamos à escola não aceitou que iniciasse de onde parei, porque como minha mãe pressupunha que o ensino era fraco. Vale lembrar que os professores, de lá, pouco apareciam, tendo em vista que escola localizava-se mata à dentro. $\mathrm{O}$ acesso era muito difícil. Eles, os professores e nós, alunos tínhamos que pegar um barco - "popopô"- muito pequeno, pois o igarapé castanhal era muito estreito, e ainda tínhamos que andar em uma trilha super complicada, só os moradores de lá a conheciam (hoje já não é mais assim). Os professores não desfrutavam de estrutura para ficar na região, uma vez que, não dava pra ir e voltar no mesmo dia, então ficavam a semana toda dessa forma e, quem acabava ensinando eram os próprios moradores que muitas das vezes mal sabiam assinar o nome.

Minha escola propriamente dita foi a "Celina Anglada" localizada no bairro do Guamá, periferia de Belém, onde morava - e moro. Bem, voltei para a primeira série, porém minha idade já era incompatível, portanto fiz um teste e passei para a segunda série e no fim do ano para a terceira. Mas não sabia nada. Meu irmão também estudava nesta escola em horário diferente, estrategicamente, pois tínhamos apenas um uniforme e um par de sandálias. Ele estudava pela manhã e eu no turno "intermediário", (hoje já não existe mais esse turno

\footnotetext{
${ }^{3}$ Coloque uma nota alertando que algumas mulheres ainda se submetem aos maridos pelos filhos, condições matriais, etc.
}

Revista PET Interdisciplinar e Programa Conexões /UFPA On-line. Ed. Especial - 2017, BELÉM/ PA - ISSN 2447-097X 
escolar) ele saía às $11 \mathrm{~h}$ e eu pegava às $11 \mathrm{~h}$. Esperava ele no meio do caminho embaixo de um "jambeiro" (lógico que enquanto esperava ficava apanhando jambo), quando chegava me dava o uniforme e a sandália. Às vezes eu caia no choro, porque ele não chegava no horário, logo não poderia entrar na escola sem o uniforme. Às vezes ele ficava jogando "peteca" e esquecia de mim, eu chorava porque se eu não entrasse na escola ia apanhar da minha mãe ou fazer os afazeres domésticos. A escola era minha fuga para não trabalhar em casa. Minha mãe não acreditava que não tinha entrado na escola quando eu dizia que o "Preto" não aparecia. Presumia, por eu ser muito danada, que eu tava aprontando. Fui uma criança muito danada, me chamavam de "Maria macho", "cara de catita", "espírito de porco" entre outros apelidos que não cabe revelar aqui...Contudo terminei a primeira parte do ensino base sem repetir nem um ano. Até hoje não sei se porque era inteligente ou se os professores queriam se livrar de mim (eu "empecilhava" a vida deles), uma vez que, eu era aluna onde ninguém queria: bagunceira, mas com boas notas.

Como a escola atendia, apenas, o ensino de primeira à quarta série, tive que mudar de escola, eu fui para Escola Estadual de ensino Fundamental Paulo Maranhão. A famosa escola dos piores alunos à época. Os pais sofriam em colocar seus filhos lá. Era conhecida como "Paulo Maranhão entra burro e sai ladrão", mas foi a única que tinha vaga para mim, cheguei a fazer uma prova para entrar numa escola pública conceituada, na época - Paes de Carvalho , mas não passei. Uma das únicas escolas que não cobravam exame para o ingresso era o Paulo Maranhão, fui para lá. Confesso que no primeiro dia de aula senti medo! A fachada da escola era toda "pichada" com símbolos de várias gangues de rua. Chamada pelos alunos de americano, pois parecia mesmo um presídio, era toda "gradiada" entrávamos na sala, e em seguida "tracanfiavam" as grades das portas e só eram abertas na hora do recreio. Durante as aulas dois policias militares ficavam andando pelos corredores, para evitar o confronto de gangues rivais. Na porta de entrada também ficavam policias revistando, pois muitas vezes foi invadida por membros de gangues para capturar rivais (alunos). Entretanto tinha seu lado bom, lá lecionavam muitos professores bons, e programas de incentivo a arte, cultura e leitura. Nesse quesito era uma boa escola! Fiz amizades que até hoje cultivo, lembrando de minha amiga Janete Duarte que, hoje, faz faculdade de educação física na UFPA. Não tenho certeza, mas da nossa turma acho que só nós e mais duas meninas conseguimos ingressar no nível superior. A maioria abandonou os estudos sem concluir. Das mulheres uma grande parte engravidou e/ou pararam de estudar.

Revista PET Interdisciplinar e Programa Conexões /UFPA On-line. Ed. Especial - 2017, BELÉM/ PA - ISSN 2447-097X 
Neste período já trabalhava como doméstica e morava no emprego. Aos finais de semana, nas folgas do trabalho ia para o cemitério Santa Isabel com meu avô lavar as sepulturas, ele, meu avô, era zelador. Confesso que gostava muito de estar lá, pois além de ganhar um "troquinho" com os serviços que fazíamos, gostava, mesmo, das mangas “suculentas". Lá é cheio de mangueiras! Minhas amigas da escola tinham medo, mas a Janete e eu íamos sempre - mãe dela também era zeladora - aproveitávamos para assustar os colegas sendo que a escola fica bem ao lado - separada apenas por um muro. Além do mais o cemitério oferecia outros atrativos para mim. Adorava ler epitáfios, saber das lindas histórias (dos defuntos) de amor: noivos que morreram juntos ou um morreu e outro em seguida por amor; das crianças que morreram e passaram a fazer milagres, mas minha preferida era a mulher do táxi: Josefina, dizem que era fascinada por carro, mas morreu atropelada no dia de seu aniversário. Depois de morta, ela, a Josefina, começou a andar de táxi, ela saia do túmulo (sem ser vista, é claro!), pegava um táxi, dizia para o motorista seguir até sua casa. Quanto o taxista bate à porta para cobrar a "corrida" o pai dela mostra três quadros na parede e pergunta qual daquelas moças pegou o táxi, quando o motorista aponta Josefina ele diz já morreu há muito tempo, mas que paga a corrida mesmo assim. Muitos motoristas juram de "pés juntos" que já levaram Josefina em seus taxis. A sepultura dela tem muitas "plaquinhas" de agradecimento aos milagres, geralmente de pessoas atropeladas. Neste cemitério há uma grande divisão social: as sepulturas da frente são dos ricos, pomposas com grandes imagens, geralmente em mármore, e jardins; as de trás, dos pobres, são os chamados "paredões", geralmente, pintadas somente com cal e um vasinho para flor. Apesar do trabalho pesado de zelar, lavar e plantar nas sepulturas foi um tempo de muito aprendizado e de aventuras.

Quando completei a $8^{\mathrm{a}}$ série tive novamente que mudar de escola. Fui para a escola Alexandre Zacharias de Assumpção, agora no turno da noite. Mudei de emprego. Comecei a trabalhar na feira do Guamá em um trailler de vendas de comida. Ganhava pouco por isso voltei a trabalhar em "casa de família" e a morar no emprego. Tinha folga a cada 15 dias.

Enquanto isso meus irmãos continuavam morando com meus pais. A cada dia a situação piorava, as brigas eram piores e o meu irmão estava crescendo e não suportando mais o sofrimento de minha mãe. Era, visível o sentimento de revolta. Os laços e valores familiares estavam prestes a serem rompidos definitivamente pela violência. Minhas irmãs, também, estavam crescendo, porém com saúde fraca, por conta da "regrada" alimentação. Minha irmã Cileia era a que mais sofria, com essa deficiência, teve vários desmaios. A diretora morava 
perto da escola, então oferecia sopa antes do começo das aulas e "cesta básica" no final do mês. Várias vezes eu fui chamada na escola por conta de ter passado mal.

Uma coisa sempre me orgulha!!! Minha mãe nunca nos deixou parar de estudar. Passasse o que passasse. Sempre disse que se estudássemos haveria um futuro melhor para nós.

Voltando. Da nova escola não tem muito que se falar. Uma escola pública "defasada", sem estrutura física - como tantas aqui no Pará - com professores desestimulados e retrógrados. Cursei a $1^{\mathrm{a}}$ série do $2^{\mathrm{o}}$ grau. Quando cursava a $2^{\mathrm{a}}$, em 2002, o Brasil foi pentacampeão mundial de futebol. Não comemorei, pois estava trabalhando e minha patroa fez questão de não me liberar. No meio do mesmo ano me dispensou, pois queria que eu parasse de estudar para cuidar de seus filhos à noite - mesmo horário em que estudava. Obviamente não aceitei e voltei para casa. Sem emprego, voltei a trabalhar na feira, no lugar de antes.

Nessas idas e vindas conheci uma pessoa muito especial: o Frank. Deste dia em diante passaria a me acompanhar em tudo. Não foi amor à primeira vista, não, foi um processo longo de conquista. Já vinha me "cortejando" há muito tempo, porém não queria me envolver sério com ninguém. Aos poucos foi me conquistando, até que cedi. Um pequeno - grande homem que passou - e ficou - em minha vida! É de grande importância citá-lo, pois deste dia em diante assumiu um papel importantíssimo na minha vida.

Trabalhei novamente na feira por alguns meses até que minha tia Maria ${ }^{4}$ foi trabalhar em uma cantina na UFPA, mais especificamente na do $\mathrm{CFCH}$ (Colegiado de Filosofia e Ciências Humanas), hoje IFCH (Instituto de Filosofia e Ciências Humanas), convidou a minha mãe para trabalhar lá, depois a mim. Comecei a trabalhar, e alguns professores do curso de ciências "pegavam no meu pé" me incentivando a prestar vestibular uma vez que já estava no último ano do ensino médio. Foi aí que comecei a construir o sonho de ingressar na universidade.

Foi amor à primeira vista, desde que tive contato com as Ciências Sociais. Observava os professores conversando, falavam coisas difíceis e interessantes que me fascinavam. $\mathrm{O}$ melhor era quando tinham programações no auditório localizado em frente à cantina palestras, seminários, workshops... - servia água e café, mas aproveitava para ficar olhando, fascinada, lembro de uma promovida pelo professor Paulo Watrin sobre indústria cultural, onde o palestrante era o professor Ernani Chaves*. Os meus olhos brilharam. Às vezes

\footnotetext{
${ }^{4}$ As Marias são todas nossas mães!
}

Revista PET Interdisciplinar e Programa Conexões /UFPA On-line. Ed. Especial - 2017, BELÉM/ PA - ISSN 2447-097X 
ficavam para almoçar, eu aproveitava e oferecia companhia, quando aceitavam indagava sobre o curso, embora quem sempre parava para me dar atenção eram os bolsistas. Na verdade alguns professores mal falavam nem me notavam ali atrás do balcão,

O caminho rumo à universidade começou, de fato, quando minha mãe ficou amiga do Cléo - bolsista - da diretoria do Instituto. Ele tinha uma amiga dona cursinho popular. Diante de minhas condições viabilizou meu encontro com ela e fui finalmente estudar. O cursinho ficava no mesmo bairro - Guamá - em uma extremidade e eu morava em outra. Visto que eu morava na fronteira com o bairro da Terra firme, considerado o mais perigoso. Deslocava-me até o cursinho de bicicleta atravessando o Guamá inteiro. Sempre brincava com os amigos do cursinho que a partir de então eu era conhecida pelo bairro todo. O cursinho chamava-se COMUNI (comunidade na universidade), com os estudos percebi a lacuna que escola pública havia me deixado. O quanto deixei de aprender, mesmo sendo considerada pelos professores uma boa aluna. Deparei-me com assuntos que nunca tinha visto e os que vi foi pela metade. $\mathrm{O}$ desespero tomou conta de mim, parecia quase impossível reaprender - aprender - 15 anos de estudos em um ano!

Quando falava que estava estudando para o vestibular, na rua onde morava, riam de mim, pois para eles também parecia impossível o meu ingresso em uma universidade. Em tese eles tinham razão, parecia impossível mesmo, mas só parecia.

No COMUNI fiz grandes amigos que me ajudaram a superar as limitações e as dificuldades. Vale lembrar-se do Milton Filho, nos tornamos amigos de "cara" dentro de um mês, amigos de infância. Tínhamos muito em comum também viemos de escola pública e gostaríamos de estudar um "ramo" das ciências humanas. Alguns atores foram de suma importância para meu ingresso no ensino superior. $\mathrm{Na}$ época os coordenadores do cursinho eram o professor John Sousa de Filosofia, História e Sociologia e o Deusenir, de Química, além de ser uma espécie de psicólogos, porque quase todos que estudavam lá passavam por muitas privações e problemas familiares e financeiros - como a maioria dos brasileiros de baixa renda. Às vezes nem conseguia assistir às aulas por conta de tantos problemas em casa. O John ouvia carinhosamente e pacientemente minhas lamúrias. Penso que ele, também, tomou para si o desafio de me colocar dentro de uma universidade. Sempre me cobrava, me incentivava, ficava no corredor esperando acabar a aula só para me explicar alguma coisa. $\mathrm{O}$ ano foi passando, e no segundo semestre de 2003 os coordenadores fizeram um simulado onde fiquei em dos últimos lugares. Tirei zero na redação. Caí no choro e ninguém conseguia me consolar. Chorei tanto que meus olhos incharam. A prova já tava próxima e a certeza de 
que não superaria o programa de estudo inteiro em alguns meses me assustava, mas não desisti continuei a estudar muito. Fiz a primeira prova e passei, fiz a segunda, e também passei, para a surpresa de todos. Quando saiu o "listão" dos aprovados, ouvia pelo rádio com muita expectativa a chamada do curso de Ciências Sociais, porém não ouvi meu nome...Passei muito mal. O Frank, meu fiel companheiro, estava lá tentando me consolar. Como no COMUNI já éramos uma família, fui para festa mesmo assim, pois uma de nossas colegas havia passado: a Neide, uma amiga que havia parado de estudar há 10 anos e já tinha 35 anos de idade. Um grande exemplo de superação para todos nós.

Começara o ano de 2004, outro vestibular. Voltei novamente para o COMUNI, agora com mais força. Já não estava mais tão "zerada”. No segundo semestre houve outro simulado e fui o primeiro lugar. Foi um sinal de que o trabalho de "alfabetização" promovido pelo COMUNI até o vestibular surtia resultados. E, novamente chega a tão esperada prova: passei da primeira, passei da segunda, na véspera da terceira prova meu pai chegou de "porre" e não nos deixou dormir, fiz a prova de ressaca, no meio da prova dormi, respondi as questões de química no cartão das de geografia. Foi um horror! O Frank já previa o meu estado na saída da prova, logo foi me buscar. Saí em prantos. Acho que chorei o dia todo. Chega a hora tão esperada do "listão" dos aprovados, mas, novamente, o meu nome não saiu. O Milton passou em Ciências Sociais, ele era muito inteligente. Fui para festa em homenagem ao meu amigo.

Em 2005 comecei novamente a estudar, desesperada, pois tinha ânsia de passar por esse rito - vestibular - era muito importante para mim, tanto pela profissionalização como pela mudança na mentalidade da minha família, sendo que ninguém teve a oportunidade de ingressar numa universidade a não ser para trabalhar.

As coisas em casa estavam piores. Chegamos a pedir para a mamãe sair de casa, pois ela não saia por nossa causa. Nós não agüentávamos mais seu sofrimento, até que teve coragem e foi com o coração na mão. Meu pai soube que fomos nós que a encorajamos e passou a ser agressivo agora conosco. Principalmente comigo, porque eu era a mais velha. $\mathrm{Me}$ expulsava de casa todos os dias, dizia que eu não era sua filha. Ainda fui à delegacia registrar ocorrência, pedindo auxílio sobre os nossos direitos e que nos deixasse ficar, pois - nós cinco - não tínhamos pra onde ir. A delegada disse que eu e meu irmão tínhamos que sair porque éramos maiores de 18 anos e os menores poderiam ficar. Ele, muito esperto, foi até a delegacia e registrou uma ocorrência contra o meu irmão, eles brigavam sempre, e pediu que nos despejassem. Já não sabia o que fazer tinha que passar no vestibular, por mim, minha mãe e meus irmãos.

Revista PET Interdisciplinar e Programa Conexões /UFPA On-line. Ed. Especial - 2017, BELÉM/ PA - ISSN 2447-097X 
Pedia para o meu patrão me liberar uma hora mais cedo. Saía as $18 \mathrm{~h}$ para dar tempo de descansar e ir para o cursinho. Ficava muito cansada, às vezes dormia durante as aulas. Ele se recusou a me liberar, então entreguei o lugar, todos ficaram chocados com minha decisão. Como viveria agora sem trabalhar? Uns achavam que estava enlouquecendo - creio que estava mesmo.

Estudei o primeiro semestre no COMUNI e fui assaltada, levaram minha bicicleta. Ficou mais difícil me deslocar para o cursinho, pois não tinha o dinheiro do ônibus e, nem mais, da mensalidade. Fiquei dois meses sem estudar até que o John havia montado um novo cursinho e ficou sabendo da minha situação e caridosamente me ofereceu uma bolsa para estudar pela manhã. Topei na hora. Quando faltavam dois meses para prova, pedi à ele para estudar também durante à tarde. Ficava o dia inteiro no cursinho, minha mãe levava comida para mim todos os dias, quando não podia o Frank levava.

Era chegada a grande hora. Na primeira prova não dormi à noite de tão ansiosa, passei com uma pontuação alta para segunda. Nesta novamente não dormi, a prova era às $8 \mathrm{~h}$, e às $6 \mathrm{~h}$ já estava pronta para ir. O Frank sempre dormia comigo em dia de prova, era, pois mais que um namorado, sempre me levava para o local da prova de bicicleta, mesmo sendo longe, tinha medo de engarrafamento - nessa data é muito comum. Fez um mingau que não consegui tomar. Saímos, mas a bicicleta estava com pneu furado. E agora?! Ele tentava me acalmar argumentando que era cedo: 6h da manhã que dava e sobrava tempo, além da escola ser perto de casa. Nesse caso fomos para o ponto de ônibus - dei sorte - logo passou o que eu esperava. Entrei e ele se despediu. Com uns 500 metros de percurso o trânsito estava engarrafado, mais ainda era cedo nem me preocupei, ainda iam dar $7 \mathrm{~h}$. O ônibus saiu do engarrafamento e com mais uns 200 metros se deparou com outro, agora bem maior. Já passavam das 7 h e nada. Passou um filme em minha cabeça, me questionava: Já estou estudando há três anos será que vou perder para um ônibus? Claro, isso já com lágrimas no rosto. Faltando 20 minutos para o início da prova, ainda, estávamos no engarrafamento, comecei a perguntar para os passageiros se iam para perto da escola que eu ia fazer prova sugerindo uma coleta para um táxi. Eu só tinha cinco reais e não bastava. De repente alguém bateu no ônibus do lado de fora. Ouvi meu nome: Shirlene...Shirlene... Olhei. Era o Frank, dizia: - desce! - desce! Ele conseguiu uma bicicleta. Feliz, em poder sair daquela estagnação eu pedi ao motorista para abrir a porta, mas ele se negou porque estávamos no meio do trânsito, logo não quis correr o risco. Supliquei que abrisse a porta, já faltavam 15 minutos. Até que um rapaz negro e alto "esmurrou" a porta dizendo que se ele não abrisse quebraria todo o ônibus. Nisso, os passageiros chorando 
comigo, até que, felizmente, abriu. Porém estávamos longe do local de prova. Com isso o Frank pedalou pelas calçadas e atalhos com toda velocidade. No retorno, já próximo à escola, avistei que o portão já estava sendo fechado e pulei da bicicleta em movimento. A porteira vendo meu desespero me empurrou para dentro e me deixou entrar. Foi um alívio! Na sala de prova e comecei chorar e a vomitar, pedi pra ir ao banheiro, lavei o rosto e voltei. Fiz minha prova, passei para terceira fase. Agora era tudo ou nada. Minha irmã, Cileia, também estava fazendo - a que desmaiava na escola - se inscreveu para biblioteconomia, sem conhecer o curso. Quando trabalhava em casa de família via sempre a amiga da minha patroa falar que o curso era bom e fácil de passar - menos concorrido -, por tanto sugeri que se inscrevesse. Ela fez uma prova em cada ano do ensino médio pelo PSS (Processo Seletivo Seriado) uma nova forma de promovida pela UFPA de selecionar. Já estava na terceira etapa, mesmo sem fazer cursinho. Aliás, só fez nesta última aos finais de semana, pois trabalhava. Diferente de mim sempre foi muito tranqüila e centrada. Fizemos a última prova juntas. Agora era só esperar a divulgação do "listão" dos aprovados.

No mesmo período meu pai ficou doente de diabetes, mesmo com restrições, não parou de beber. Numa de suas farras, na volta para casa foi assaltado e espancado, em conseqüência saiu com uma perna quebrada. Foi internado e fiquei com ele no hospital. Voltei pra casa para buscar roupas no dia seguinte estava previsto dele sua alta. Quando saía de casa minha mãe me aborda, fiquei surpresa em vê-la, pois nunca mais aparecido em casa após a separação e me perguntou se estava de saída e para onde ia. Disse que ia buscar o Pai, já de alta do hospital. Pediu que eu não fosse, pois a divulgação dos aprovados foi confirmada para esse dia e que eu mandasse uma de minhas tias - irmãs dele- ir buscá-lo.

Fiquei atônita, sem reação e liguei para meu namorado para avisar, mas ele já sabia me convidou para ir para casa dele, me distrair, pois fiquei muito nervosa. Quando chego lá chego lá eles estavam com o som alto, a irmã dele me abraçou chorando, dizendo que eu tinha conseguido que viu meu nome no "listão" da Internet. Sem crer fomos a um cyber, mas o dono do estabelecimento afirmou que estava previsto para $10 \mathrm{~h}$, ainda eram $8 \mathrm{~h}$ da manhã. Ele insistia. Até que fomos para a casa de um tio meu que tinha Internet, a rede estava um pouco lenta, quando finalmente conseguiu acessar. Gritou dizendo que, realmente, havia saído. Todos correram para ver, a casa ficou cheia. Viram primeiro o da minha irmã para surpresa havia passado. Chegou a minha vez, alguém foi olhar eu estava sentada em uma cadeira encostada na parede, só ouvi o poxa..., meu tio - enorme de gordo - veio em minha direção com passos pesados, disse:

Revista PET Interdisciplinar e Programa Conexões /UFPA On-line. Ed. Especial - 2017, BELÉM/ PA - ISSN 2447-097X 
- Minha filha vestibular tem todo ano, tu ainda és nova a vida não acaba, bola pra frente. Você não passou de novo!

Mas não acreditei. Queria ver com meus próprios olhos. Todos já lamentavam por todo meu esforço ter ido, novamente, por água a baixo. Me aproximei do computador e percebi que haviam olhado o curso errado - matutino e o meu era noturno. Rapidamente verifiquei o correto. Nem precisei procurar tanto o maior nome era o meu - SHIRLENE DO SOCORRO COELHO SANTOS -, se destacava aprovada em $13^{\circ}$ lugar. Daí foi só festa!

Entrei na UFPA!!!!!!!!!!!!!!!!!!!!!!!!!!!! 